\title{
Seismic detection of sonic booms ${ }^{\text {a) }}$
}

\author{
Joseph E. Cates ${ }^{\text {b) }}$ and Bradford Sturtevant \\ Graduate Aeronautical Laboratories, California Institute of Technology, Pasadena, California 91125
}

(Received 18 July 2001; revised 29 August 2001; accepted 30 August 2001)

\begin{abstract}
The pressure signals from a sonic boom will produce a small, but detectable, ground motion. The extensive seismic network in southern California, consisting of over 200 sites covering over 50000 square kilometers, is used to map primary and secondary sonic boom carpets. Data from the network is used to analyze three supersonic overflights in the western United States. The results are compared to ray-tracing computations using a realistic model of the stratified atmospheric at the time of the measurements. The results show sonic boom ground exposure under the real atmosphere is much larger than previously expected or predicted by ray tracing alone. Finally, seismic observations are used to draw some inferences on the origin of a set of "mystery booms" recorded in 1992-1993 in southern California. (C) 2002 Acoustical Society of America.
\end{abstract}

[DOI: $10.1121 / 1.1413754]$

PACS numbers: 43.28.Mw, 43.20.Dk [LCS]

\section{INTRODUCTION}

The seismic network in southern California routinely detects sonic booms from aircraft. The high density of sites and the extensive ground coverage of the network, over 50000 square kilometers, provide a unique opportunity to study the long-range propagation of direct and indirect sonic booms.

In Sec. II, the fundamental features of sonic boom carpets under a realistic atmosphere are presented. The pressure signals from the $\mathrm{N}$-wave signal in the atmosphere produce a small, but detectable, ground motion as outlined in Sec. III. Seismic data from three overflights are presented in Sec. IV: a west to east SR-71 pass at $M=3.15$, the landing of space shuttle Discovery, STS-42, at Edwards AFB, and the passage of shuttle Discovery over Washington and Oregon. Section V presents the results of an analysis of a set of "mystery booms" which occurred in California in 1992 and 1993.

\section{ATMOSPHERIC PROPAGATION}

For the propagation of sonic booms through the atmosphere, the linear theory of geometrical acoustics is applied. In geometrical acoustics, the shock front moves along rays with speed $c$ relative to the surrounding medium, where $c$ is the local sound speed. Following Pierce (1981), the raytracing equations can be written

$$
\begin{aligned}
& \frac{\mathrm{d} \mathbf{x}}{\mathrm{d} t}=\frac{c^{2} \mathbf{s}}{\Omega}+\mathbf{v}, \\
& \frac{\mathrm{d} \mathbf{s}}{\mathrm{d} t}=-\frac{\Omega}{c} \nabla c-\mathbf{s} \times(\nabla \times \mathbf{v})-(\mathbf{s} \cdot \nabla) \mathbf{v},
\end{aligned}
$$

where $\mathbf{n}$ is the unit normal to the wave, the medium moves with velocity $\mathbf{v}$, the wave-slowness vector $\mathbf{s}=\mathbf{n} /(c+\mathbf{v} \cdot \mathbf{n})$, and $\Omega=1-\mathbf{v} \cdot \mathbf{s}=c /(c+\mathbf{v} \cdot \mathbf{n})$. A stratified model is typically assumed for the atmosphere where properties vary only with

\footnotetext{
${ }^{\text {a) }}$ Portions of this work were presented as "Studies of sonic booms with seismic networks," 129th Acoustical Society of America meeting, 30 May-3 June 1995, Washington, DC.

${ }^{b}$ Presently at Universal Music Group, Universal City, CA.
}

altitude $[\mathbf{v}=\mathbf{v}(z), c=c(z)]$, and the vertical wind velocity is zero $\left(v_{z}=0\right)$. For this case, the equation for the change of $\mathbf{s}$ simplifies to a generalization of Snell's law. The horizontal components $s_{x}$ and $s_{y}$ must remain constant, while the vertical component is given by

$$
s_{z}= \pm\left[\left(\frac{\Omega}{c}\right)^{2}-s_{x}^{2}-s_{y}^{2}\right]^{1 / 2} .
$$

The ray equations become

$$
\frac{\mathrm{d} x}{\mathrm{~d} t}=\frac{c^{2} s_{x}}{\Omega}+v_{x}, \quad \frac{\mathrm{d} y}{\mathrm{~d} t}=\frac{c^{2} s_{y}}{\Omega}+v_{y}, \quad \frac{\mathrm{d} z}{\mathrm{~d} t}=\frac{c^{2} s_{z}}{\Omega} .
$$

From the assumption of a stratified atmosphere, the righthand side of Eqs. (4) are functions of altitude alone and can be integrated numerically from atmosphere profiles.

Rays are confined to regions of sound speed and wind speed where $s_{z}^{2}>0$. A turning point exists where $s_{z}$ passes through zero and the ray changes direction of vertical propagation. For an atmosphere without winds, a ray will only turn horizontal at the altitude with sound speed

$$
c\left(z^{*}\right)=\frac{c_{0}}{\cos \theta_{0}},
$$

where $c_{0}$ and $\theta_{0}$ are the sound speed and ray angle to the horizontal at the point where the ray is emitted. For the case of a sonic boom, the ray is emitted at the complement of the Mach angle. Therefore, the ray turning points for an aircraft in straight and level flight are located at the altitude where the sound speed is equal to the velocity of the aircraft. For an aircraft flying at below the ambient sound speed at the ground, all rays will be turned and none will reach the ground. This critical Mach number is referred to as the cutoff Mach number. Rays which are turned at high altitude will reach the ground only if the sound speed is greater than that at the ground; otherwise, the ray will be channeled between an upper and lower turning point.

For long-range propagation in the atmosphere, the effect of winds cannot be neglected. For a stratified atmosphere with winds, the turning points for each ray depend on the ray 


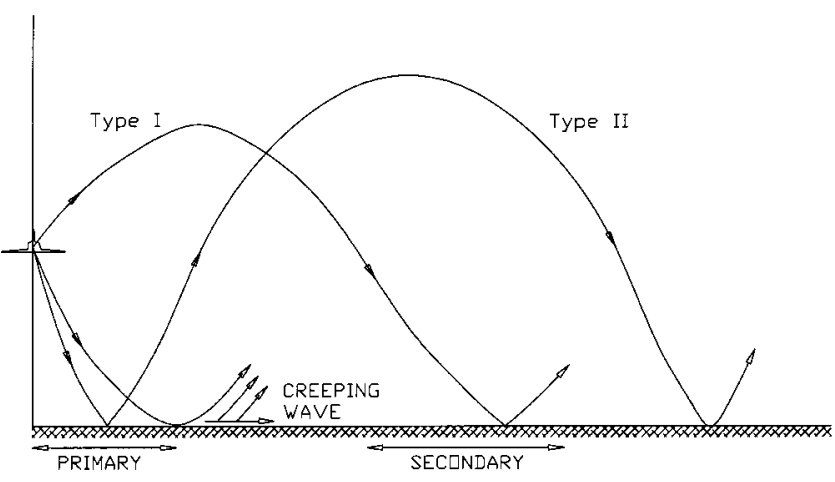

FIG. 1. Illustration of sonic boom carpets.

direction. It is convenient to define the effective sound speed seen by a ray moving in a particular direction $c_{\text {eff }}=c_{0}+\mathbf{v}$ - n. The turning point for a ray occurs at the altitude where

$$
c_{\mathrm{eff}}\left(z^{*}\right)=\frac{c_{0}}{\cos \theta_{0}},
$$

which depends on the ray direction through the effective sound speed.

For a uniform atmosphere with no winds, the sonic boom forms a Mach cone which intersects the ground to produce the hyperbolae typically associated with the sonic boom footprint. For realistic atmosphere profiles, the sonic boom footprint becomes much more complex, as shown in Fig. 1. The primary carpet lies directly beneath the aircraft and consists of direct rays from the aircraft to the ground. The increasing temperature as rays approach the ground leads to the refraction of the rays upward which limits the width of the primary carpet. Outside of the primary carpet, a secondary carpet is formed of indirect rays which have propagated upward and been refracted back to the ground. Additional carpets are formed further from the aircraft flight path by rays which have reflected from the ground, returned to high altitude, and then back toward the ground. Even higher-order carpets exist further out from the flight path.

Between the primary carpet and secondary carpet, geometrical acoustics predicts a shadow region where no rays
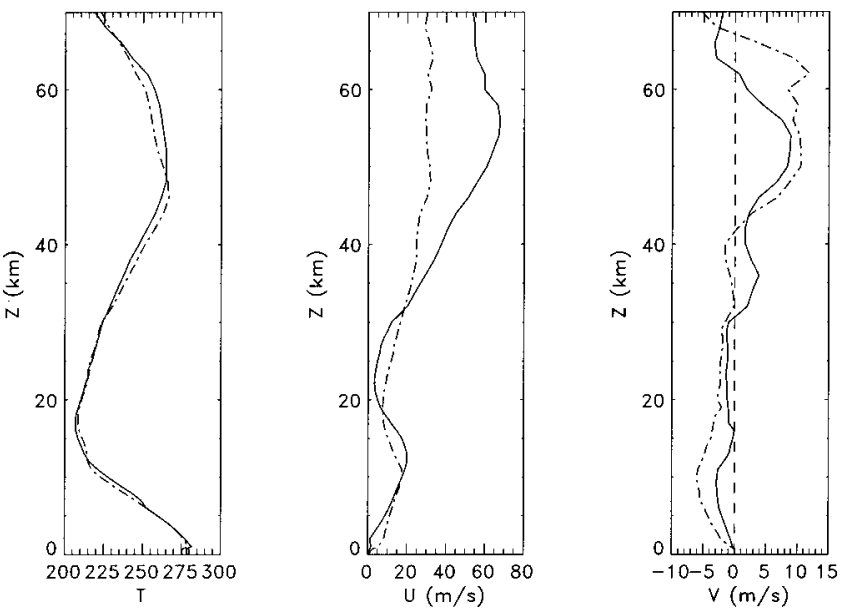

FIG. 2. Temperature and zonal (east/west, $U$ ) and meridional (north/south, $V)$ wind component profiles for January (_- ) and November $(-\cdot-)$, Edwards AFB Range Reference Atmosphere.

reach the ground. However, the full theory of acoustics allows for a creeping wave launched at the edge of the primary carpet which propagates along the ground in the ray direction. The creeping wave is typically illustrated as a wave moving along the ground continually launching rays upward. Since the creeping wave sheds energy, the amplitude dies off exponentially with distance (Rickley and Pierce, 1980).

For the present analysis, the Range Reference Atmosphere for Edwards Air Force Base is used for wind and thermodynamic properties to $70 \mathrm{~km}$ altitude (Meteorology Group, Range Commanders Council, 1983). These profiles are comparable to the U.S. Standard Atmosphere, Supplemental Atmosphere (1966), and climatic data for the Pacific Missile Range, CA (de Violini 1967, 1969). In Fig. 2, profiles of temperature and zonal and meridional wind components are shown as a function of altitude from the monthly profiles for January and November. Zonal winds are positive when from west to east and meridional wind components are positive when from south to north. During the winter months, the zonal wind component shows strong stratospheric winds blowing from west to east. Meridional wind
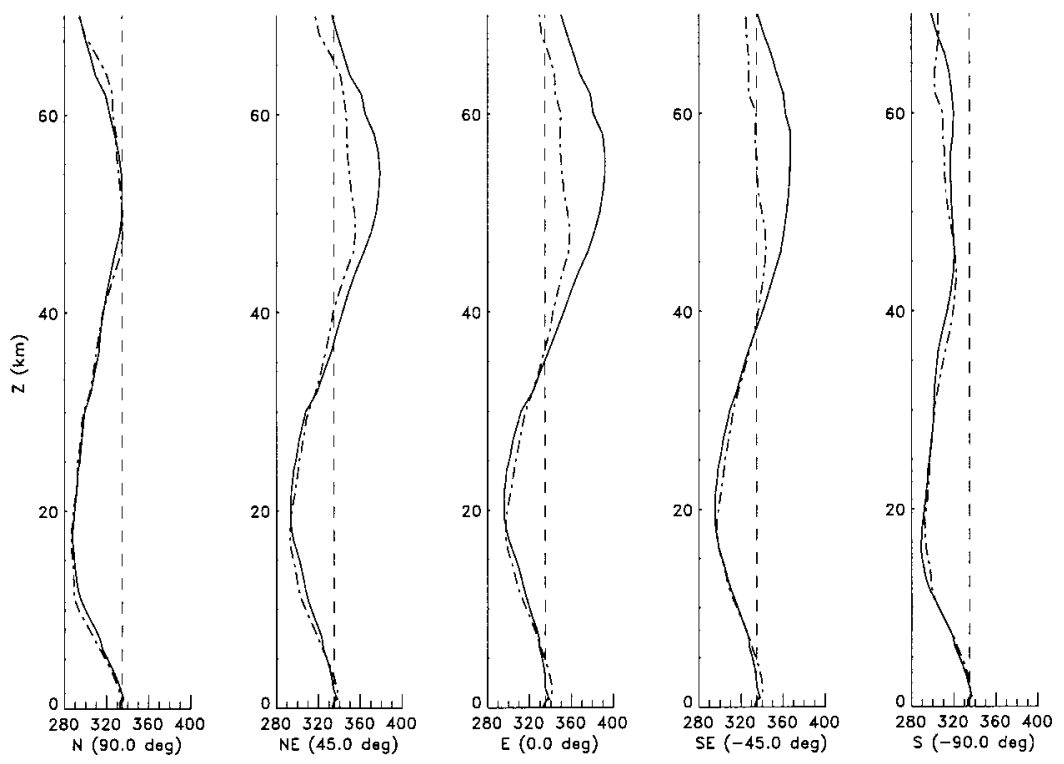

FIG. 3. Effective sound speed profiles for January (- $)$ and November (---), Edwards AFB Range Reference Atmosphere. 

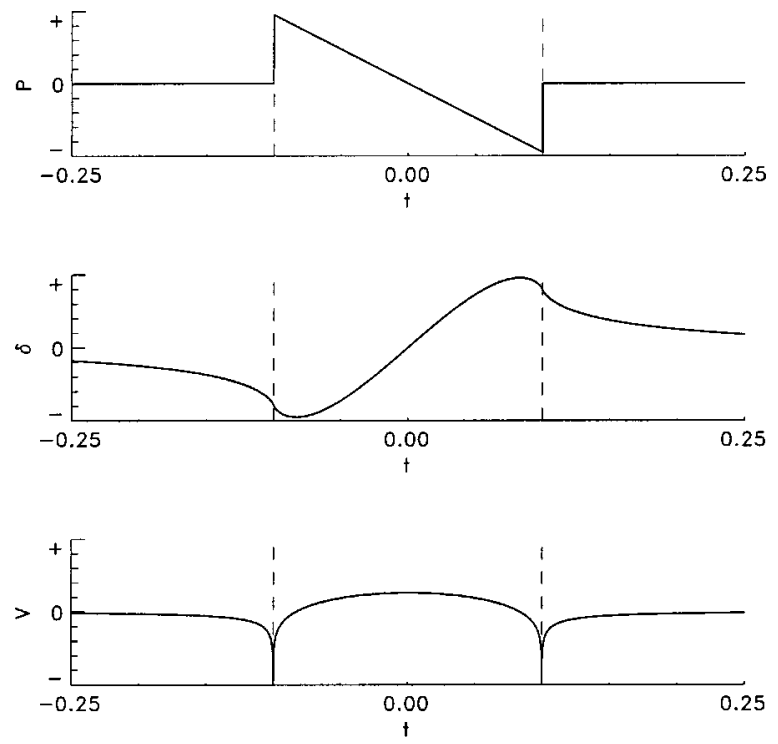

FIG. 4. Surface effects of pressure wave.

components are much weaker and tend to fluctuate in direction, although stronger meridional wind components are also found at stratospheric altitudes.

Effective sound speeds for five ray directions are shown in Fig. 3. Shallow rays traveling east will be turned downward toward the ground between 40 and $60 \mathrm{~km}$ altitude. The effective sound speed for rays traveling directly north or south is not sufficiently high at altitude to diffract the rays to the surface, but a significant area of high effective sound speeds exists even for the northeast and southeast directions. Rays traveling west will not be turned back to the ground at any altitude. The temperature rise in the stratosphere alone is not sufficient to return rays to the ground.

Examples of these atmospheric effects have been observed experimentally for sonic booms. Rickley and Pierce (1980) measured secondary sonic booms from Concorde flights along the East coast of the United States. Microphones captured similar indirect sonic booms from the Concorde refracted from the level of the stratosphere $(40-50 \mathrm{~km})$ which had propagated a horizontal range of over $165 \mathrm{~km}$. These were followed several minutes later by low-frequency signals which had refracted from the level of the thermosphere (100-130 km) and propagated over ranges up to 1000 km (Balachandran et al., 1977). Sonic boom signatures are often recorded past the nominal edge of the primary carpet; however, the occurrence of creeping waves is difficult to detect due to the similar effects of turbulent scattering (Onyeowu, 1975).

Although pointwise pressure measurements have been made for indirect sonic booms, fundamental questions about the size and shape of the indirect carpets and the shadow regions remain unanswered. Measurement of indirect sonic booms has traditionally been very difficult due to the locational dependence on the atmospheric conditions at high altitude and the wide geographic coverage required to resolve the carpets. As shown in the next section, existing seismic networks, such as the network in southern California which covers over 50000 square kilometers, provide a very useful tool for analyzing the indirect sonic booms.
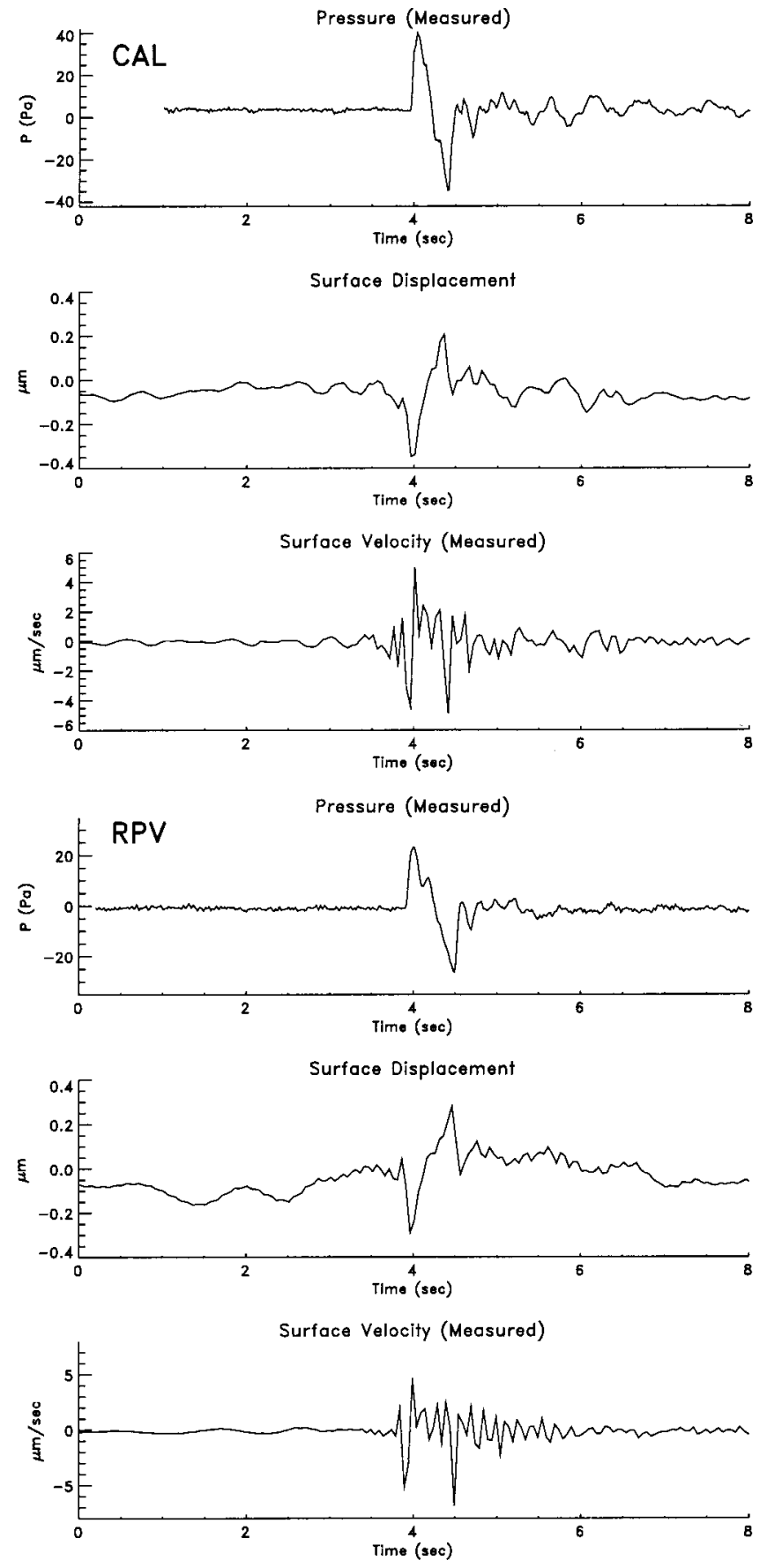

FIG. 5. Pressure, surface displacement, and surface velocity for TERRAscope sites CAL (Cal State LA) and RPV (Rancho Palos Verdes) for the reentry of space shuttle Endeavour, March 1995. (Data provided by Dr. H. Kanamori, Caltech Seismological Laboratory.)

\section{SEISMIC DETECTION}

Early use of seismographs in sonic boom research was primarily restricted to examining the effects of sonic booms on ground motion and the possibility of damage to structures or triggering of earthquakes (Cook and Goforth, 1970). These studies involved only a few seismograph instruments, often specifically emplaced for the overflights. Only recently have larger existing seismograph networks been used to detect sonic booms from aircraft and meteors (Kanamori et al., 1992; Qamar, 1993).

Due to the much higher sound speed in the surface, the 


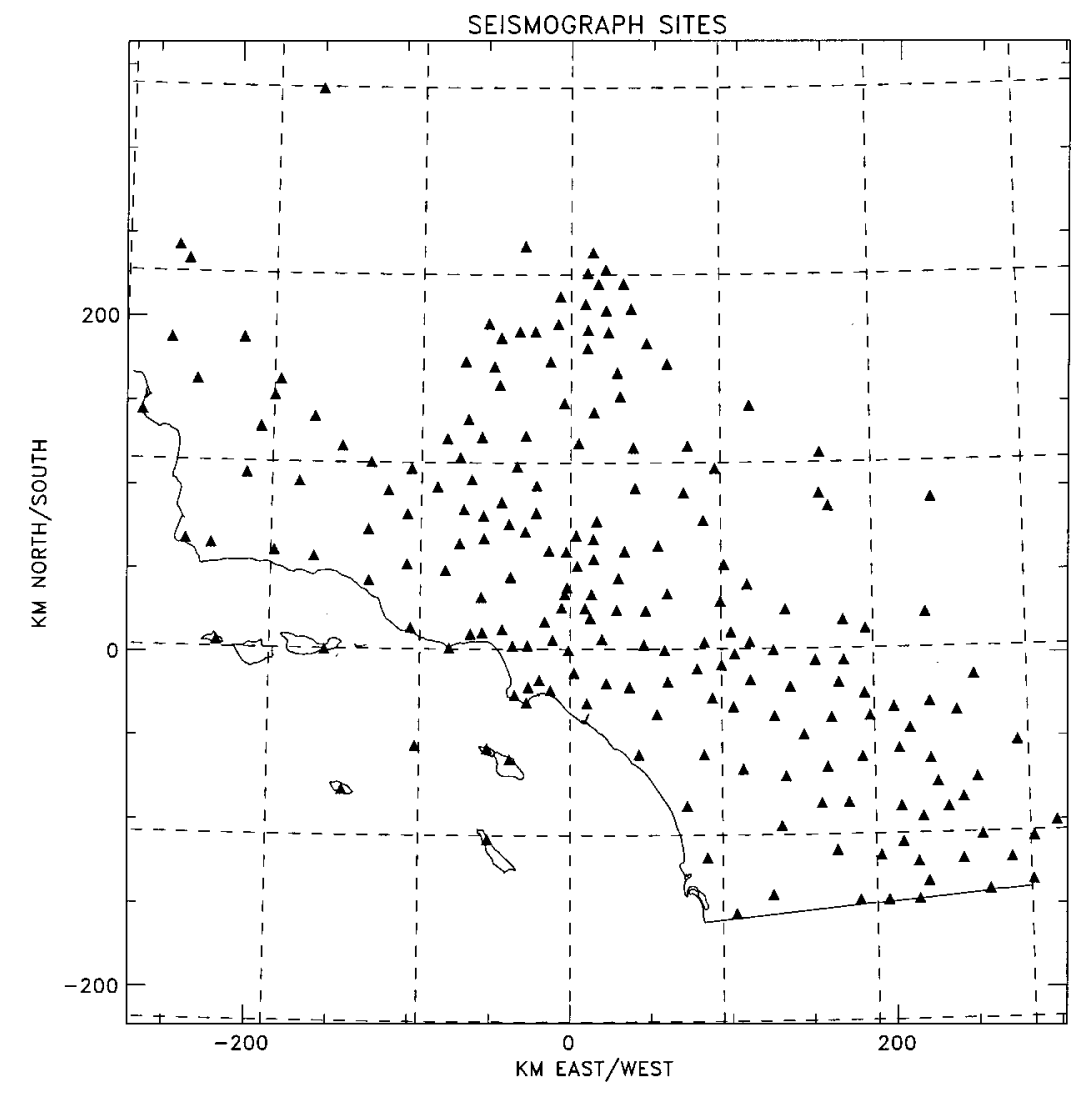

FIG. 6. Seismic stations in California used for the current study.

majority of the energy of the $\mathrm{N}$-wave is reflected; however, several effects of the wave are observed in the ground. The primary effect of the pressure wave is the moving strain field in the surface immediately beneath the $\mathrm{N}$-wave. A secondary, weaker effect is the production of coupled Rayleigh waves which follow the passage of the N-wave. In addition, irregu-

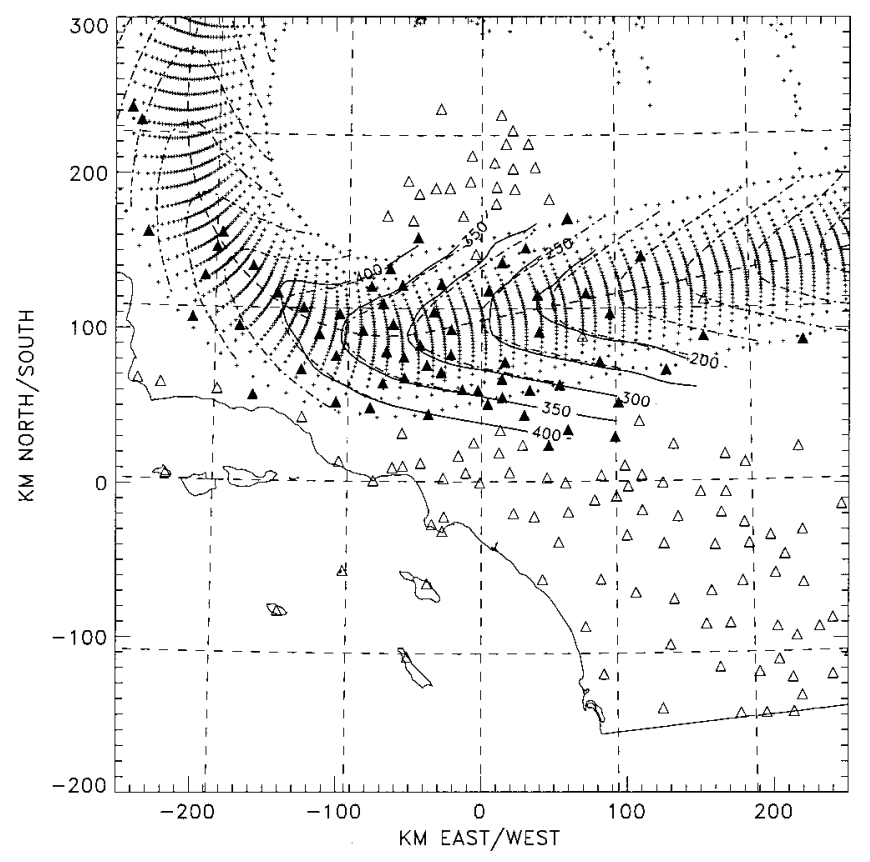

FIG. 7. Contours from seismic arrival times (- compared with raytracing results (-.-) for SR-71 flight, 8 December 1993, at $M=3.15$, altitude $21 \mathrm{~km}$. The small plus symbols represent where rays from ray-tracing intersected the ground. larities in the ground properties and acoustic coupling with geographical features become local sources which radiate additional seismic waves. Since the wave speed is higher in the ground, precursor waves are often observed to arrive several seconds before the sonic boom (Cook and Goforth, 1970).

If the shock wave is approximated as a moving normal load over an elastic half-space, the displacement and velocity of the surface can be computed from a superposition of solutions producing zero normal and shear stress at the boundary. Consider an incident wave moving along the surface at velocity $U$ with pressure distribution

$$
p(x, t)=p_{0} e^{i \omega(t-x / U)} .
$$

The vertical displacement $u_{z}$ at the surface is given by

$$
u_{z}(x, t)=-\frac{U p_{0}}{2 \mu \omega}\left(\frac{\lambda+2 \mu}{\lambda+\mu}\right) e^{i \omega(t-x / U)},
$$

where $\lambda$ and $\mu$ are the elastic constants of the half-space (Ben Menachem and Singh, 1981). The surface velocity follows immediately by derivation of the displacement. The theoretical surface displacement and velocity predicted by Eqs. (7) and (8) for a pressure $\mathrm{N}$-wave with duration $\tau=0.2$ are shown in Fig. 4. The surface velocity diagram shows the inverted U-type of signature characteristic of an $\mathrm{N}$-wave for velocity seismograms. The two strong downward peaks correspond to the leading and trailing shock on the original $\mathrm{N}$-wave.

Pressure transducers have been added to a number of the TERRAscope stations in southern California operated by the Caltech Seismological Laboratory. This allows direct comparisons between sonic boom pressures and surface velocity. 

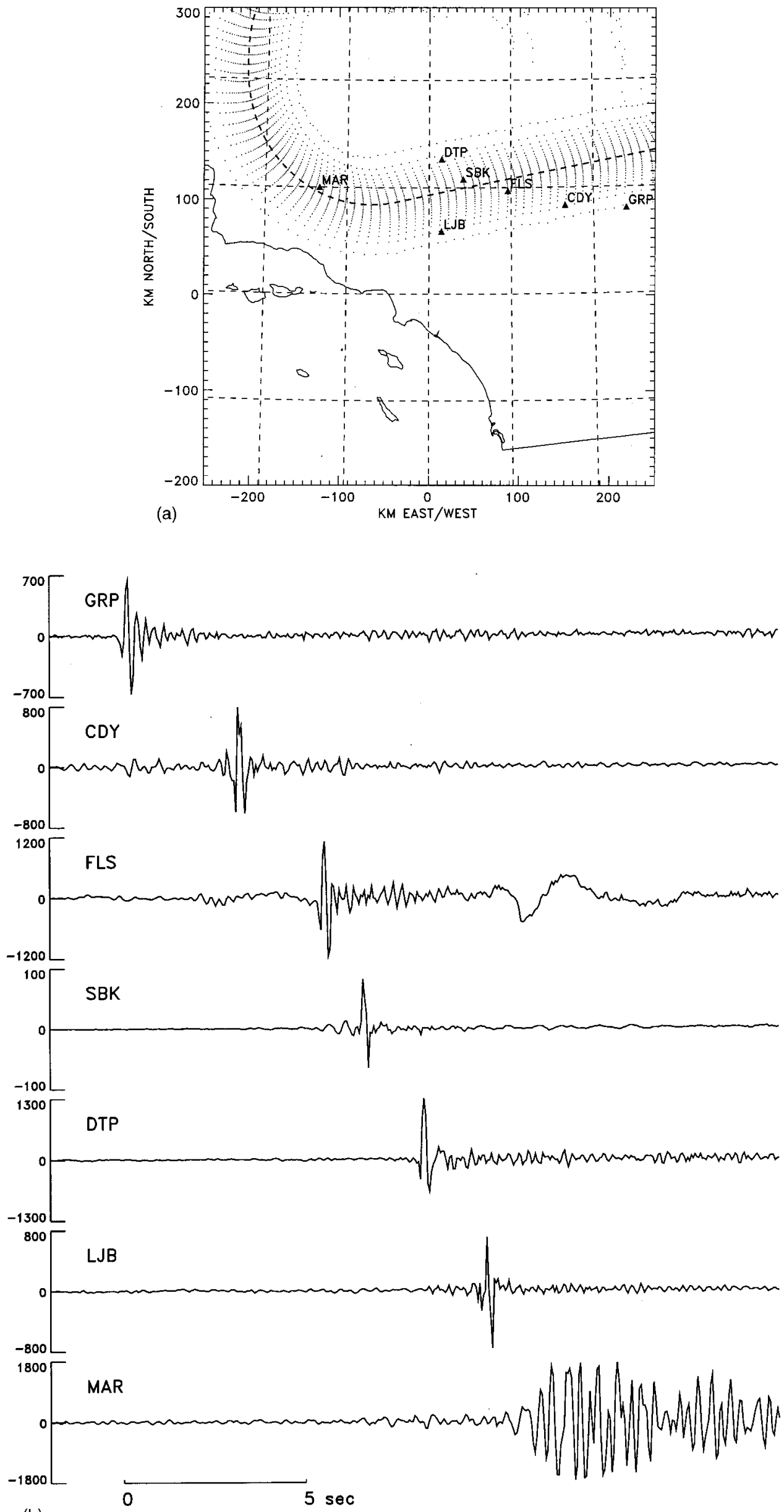

FIG. 8. (a) Seismic station locations relative to SR-71 trajectory and (b) time traces from selected seismic stations which detected the primary boom. Time traces record ground motion, vertical scale is voltage output in counts.

(b) 
In Fig. 5, data are shown for the two TERRAscope stations CAL (CalState LA) and RPV (Rancho Palos Verdes) for the reentry of space shuttle Endeavour on 18 March 1995. (Data provided by Dr. H. Kanamori, Caltech Seismological Laboratory.) The pressure and surface velocity are measured directly and corrected only for instrument response, and the surface displacement is integrated from the velocity. The characteristic double-peaked signature of an $\mathrm{N}$-wave is clearly visible in the surface velocity traces which provides an accurate estimate of the $\mathrm{N}$-wave duration. The features of the $\mathrm{N}$-wave are also captured very well in the surface displacement.

The seismic network used in the current study consists of over 200 stations shown in Fig. 6 from TERRAscope (Caltech's broadband seismic network), the Caltech-U.S.G.S. Southern California Seismic Network (SCSN), and the University of California Los Angeles Basin Seismic Network. The majority of sites are SCSN stations which measure ground motion velocity in the frequency range of 1 to $20 \mathrm{~Hz}$. These instruments record frequencies well within this range, but response falls off above $20 \mathrm{~Hz}$ due to an anti-aliasing filter near $30 \mathrm{~Hz}$. Only a limited response is available below $1 \mathrm{~Hz}$. Raw output voltage data were provided at 100 samples per second by Dr. H. Kanamori, Caltech Seismological Laboratory, and Dr. J. Mori, U.S.G.S., Pasadena. For magnitude analysis, the data were corrected for instrument response; otherwise, the raw signal data were used for selecting arrival times.

For the entire network, amplitude information is difficult to extract from the seismic data due to the lack of detailed knowledge of the local surface conditions of the seismic stations. When the site and instrument properties are known, seismic data have been shown to produce accurate estimates of $\mathrm{N}$-wave pressures for the primary sonic booms from shuttle landings (Kanamori et al., 1992). However, for the extensive network used in this study, the sites are typically classified only as hard or soft rock sites. A useful approximation for at least a basic comparison of pressures is available from Goforth and McDonald (1968). In flight tests with a wide variety of aircraft using velocity seismographs with a frequency range of 1 to $100 \mathrm{~Hz}$, the peak ground velocity was found to be proportional to the maximum overpressure: for high-density rock, maximum ground velocity was approximately $1.5 \mu \mathrm{m} / \mathrm{s}$ per Pa of overpressure, and approximately $2 \mu \mathrm{m} / \mathrm{s}$ per Pa for low-density rock.

The seismograph records provide accurate information for arrival time of the pressure disturbances. When the signal characteristic of $\mathrm{N}$-waves is visible, the duration of the $\mathrm{N}$-wave can also be determined. However, at soft-rock sites, the actual $\mathrm{N}$-wave signal itself is often lost in reverberations of the local sediment. Due to the extremely low magnitude of the ground motion, disturbances often are indistinguishable from local sources such as noise or nearby traffic. Events which are not also observed on nearby sites have to be ignored as local noise when choosing arrival times from the time traces.

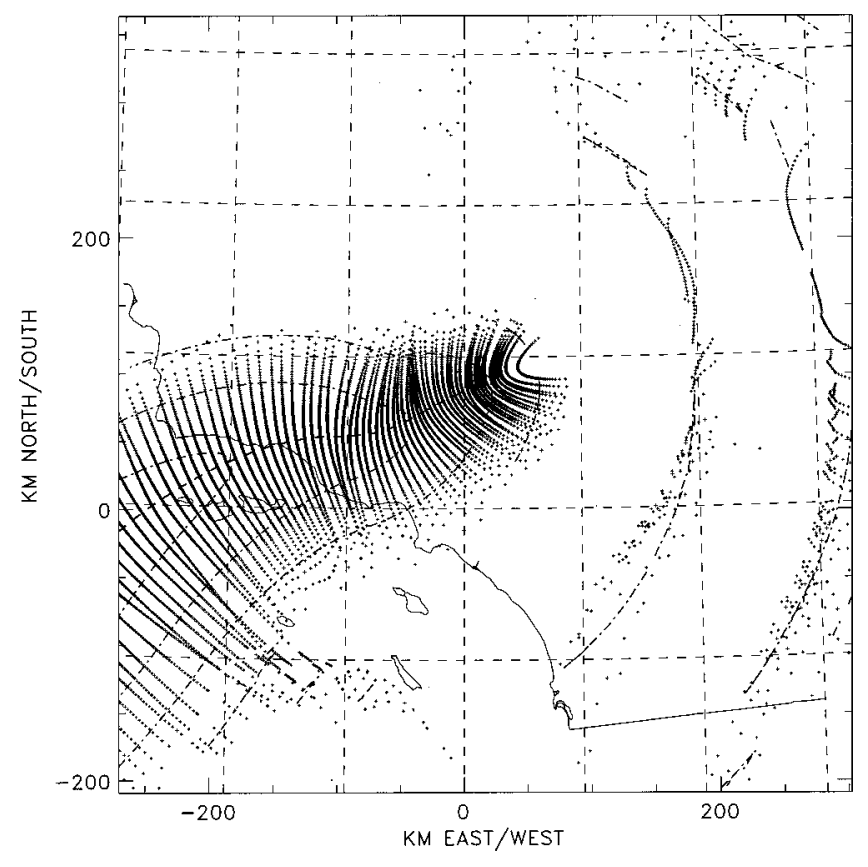

FIG. 9. Ray-tracing results for STS-42 reentry showing points where rays intersected the ground $(+)$ and contours of arrival times $(-\cdot-)$.

\section{FLIGHT RESULTS}

\section{A. SR-71 Mach 3.15 overflight}

First, due to the relative complexity of the space shuttle reentry trajectories, the results from a portion of a NASA SR-71 flight on 9 December 1993 are presented. As part of a prescheduled flight, the SR-71 flew a high-speed pass from east to west over Edwards AFB at $M=3.15$ at an altitude of $21 \mathrm{~km}$. Through the kind cooperation of Dr. Robert Meyer of NASA Dryden, the SR-71 trajectory was modified to facilitate collection of seismic data.

The seismic data from the overflight are shown in Fig. 7. All seismic stations available are denoted by the triangle symbols, and solid symbols denote the sites which detected the sonic boom. The arrival time data were converted to a regular grid and contoured to produce the solid arrival time contours. Since the majority of the rays are propagating east to west, no indirect carpets are observed. The seismic data clearly show both the north and south edges of the primary carpet.

For comparison, a ray-tracing computation was performed. A cone of rays was launched at the Mach angle at discrete times along the trajectory, and the rays were then propagated using the wind and temperature profiles from the Edwards AFB Range Reference Atmosphere (Meteorology Group, Range Commanders Council, 1983). The small plus symbols in Fig. 7 represent the locations where the computed rays intersected the ground. The majority of the ray ground intersections are direct rays in the primary carpet underneath the aircraft trajectory; only a few indirect rays appear north of the primary carpet. The ground arrival time contours from ray tracing are shown as dashed lines. The ray-tracing contours compare well with the arrival times from the seismic data, with the only significant disagreement being a loss of 

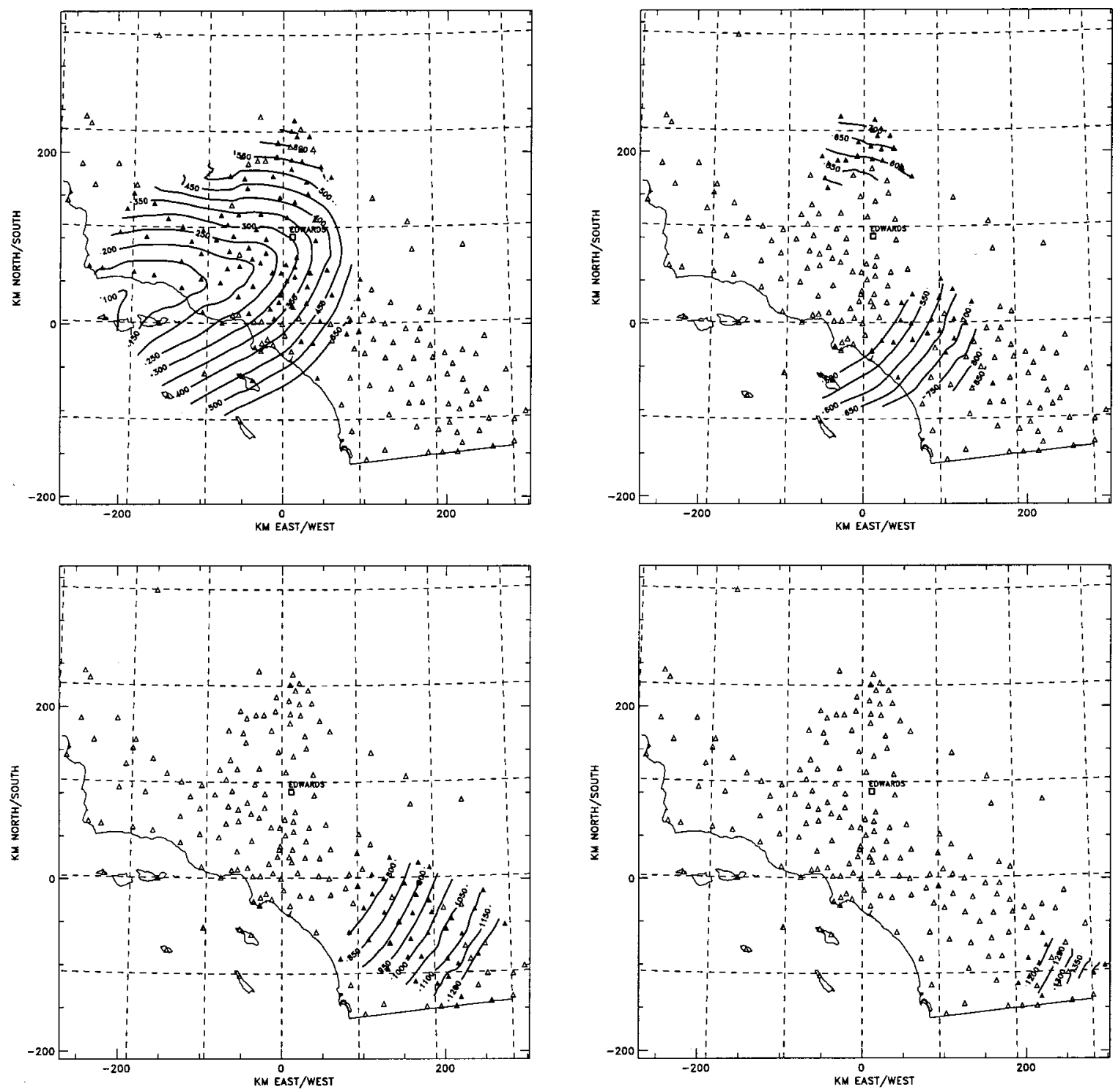

FIG. 10. Contours from seismic arrival times, STS-42 reentry.

resolution due to the lack of sites as the aircraft begins to turn north.

Sections of the seismic traces for seven sites from the SR-71 flight are shown in Fig. 8. The time traces show the ground velocity signal characteristic of an $\mathrm{N}$-wave. The MAR site is shown as an example of a site where the signal is lost in reverberations in the ground layers. Precursor waves are seen before several of the $\mathrm{N}$-wave signatures, most notably at the SBK site. This example provides an important verification that the seismic data do not show spurious signals, but only the signal from the $\mathrm{N}$-wave.

\section{B. STS-42 reentry}

The seismic data were examined in detail for the landings at Edwards AFB of space shuttle Discovery, STS-42, on 30 January 1992. The flight approached Edwards AFB from the west over the Pacific Ocean, leading to rays which propagated predominantly from west to east producing a complex set of indirect sonic boom carpets.

Contours of arrival time from ray-tracing results for the reentry of STS-42 are shown in Fig. 9. A cone of rays was launched at the Mach angle at discrete times along the trajectory, and the rays were then propagated through the wind and temperature profiles. The small plus symbols represent the locations where computed rays intersected the ground. The shuttle trajectory is shown as a dashed line. Within the primary carpet, the arrival time contours shown as dashed lines have the characteristic hyperbolic shape, modified by the maneuvering of the shuttle. The shockfront predicted by ray tracing is crossed and folded within the primary carpet, which is manifested as the crossing of the locus of the ground intersection points for rays emitted at subsequent times. As the altitude and Mach number decrease, the width of the primary carpet decreases. In addition to the primary carpet, two indirect carpets to the east are apparent, separated by shadow regions where no rays reach the ground from ray-tracing.

The seismic network detected four booms from the STS-42 landing. Arrival time contours from the seismic data for the four booms are shown in Fig. 10. Arrival times are chosen from the time traces, converted to a regular grid, and contoured at $50 \mathrm{~s}$ intervals. The most immediately striking 

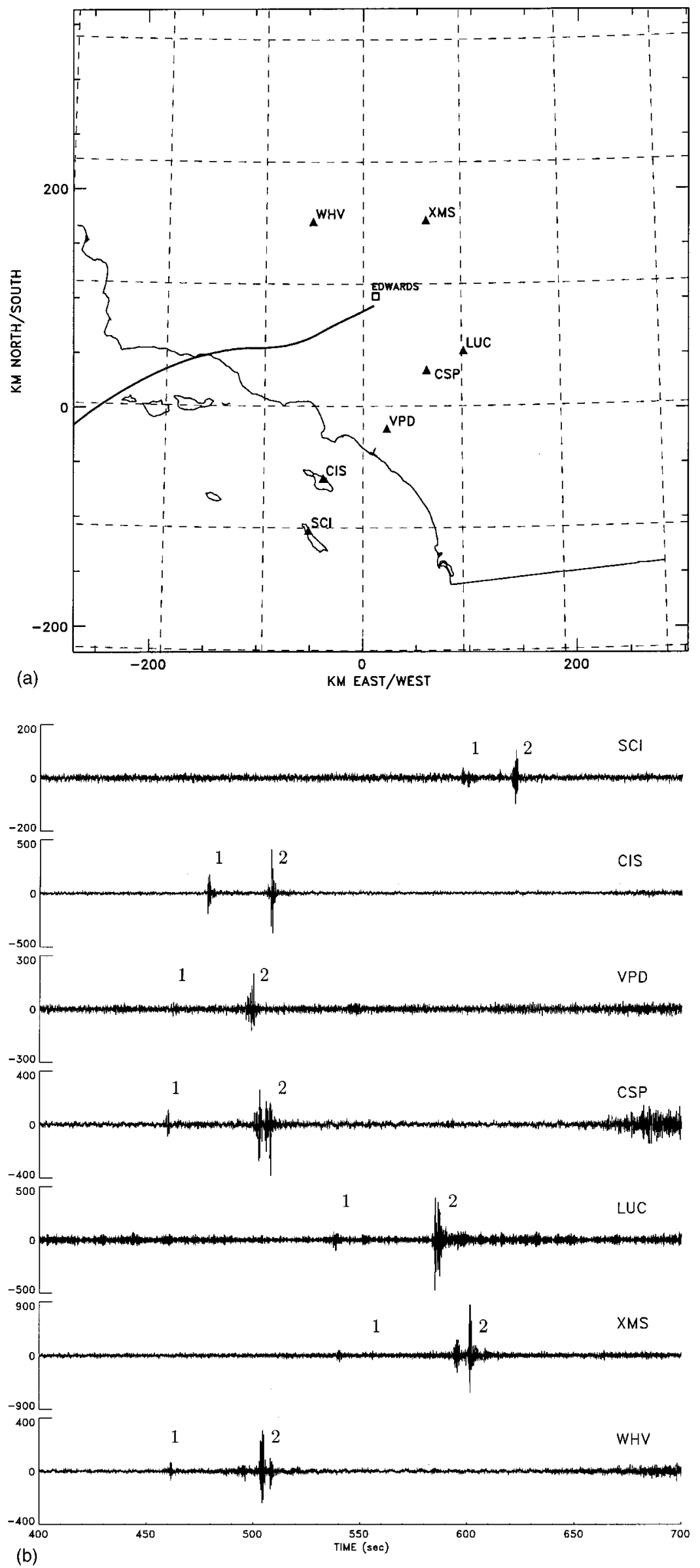

FIG. 11. (a) Seismic station locations relative to the STS-42 trajectory and (b) time traces from selected seismic stations within the shadow region predicted by ray-tracing for STS-42 reentry. Time traces record ground motion, vertical scale is voltage output in counts.

(b) 
feature of the seismic results is the complete ground coverage. Virtually the entire network detected at least one boom, and no shadow region is visible, which is in contrast to the ray-tracing results (Fig. 9). Within the primary carpet, the contours agree very well with the ray-tracing results, verifying again the ability of the seismic network to accurately map the primary carpet.

Due to the rather unexpected amount of ground coverage of the sonic booms, three sets of representative time traces are shown in Figs. 11-13. The first figure, Fig. 11, shows seven seismic sites situated in the shadow region predicted by geometrical acoustics. The sites, both north and south of the trajectory, show two booms within the shadow region. The first boom is almost certainly the primary boom, labeled boom 1. This is consistent with the underprediction of the carpet width by ray-tracing as was observed for the SR-71 overflight. The second boom, labeled boom 2, may be a creeping wave, although the magnitude appears too large. Attempts to vary the atmosphere profile, such as introducing unusually strong jet stream winds, failed to duplicate the second boom in this region by ray-tracing.

The second figure, Fig. 12, shows seven sites in an area roughly $100 \mathrm{~km}$ square, slightly inside the secondary carpet predicted by ray-tracing. Boom 2 appears on each of the sites but splits into two peaks on the eastern sites, for example at the MDA and RAY sites. The low-amplitude disturbance seen on these sites appears to be a third and fourth disturbance, labeled booms 3 and 4, which strengthens and becomes clearly visible further east. The final set of time traces for STS-42 reentry, Fig. 13, shows a line of seven sites stretching $150 \mathrm{~km}$, offering a rare opportunity to view the development of the indirect carpets. The second boom, boom 2 , is seen to disappear further from the flight track to be replaced by booms 3 and 4 . The indirect booms are split into two segments, which one would assume is caused by discrete bands in the atmosphere profiles.

\section{Discovery reentry}

A network of seismic stations in Washington and Oregon detected the 9 December 1992 reentry of space shuttle Discovery (Qamar, 1993). Figure 14 shows contours of arrival times from 66 seismic sites covering both sides of the flight track for distances of over $500 \mathrm{~km}$. Arrival times supplied by Qamar have been converted to a regular grid and contoured without any assumptions about the original trajectory. The strong curvature of the contours and the relatively sparse data result in the oscillations seen along the contours; however, the outline of the hyperbolae in the primary carpet is clearly visible.

Sections of the time traces for the seven labeled stations are shown in Fig. 15. The stations are plotted in order of the arrival of the signal, i.e., north to south; however, the time origin is shifted to align the arrival of the primary disturbance. The later stations show two disturbances which Qamar postulated were the two peaks of the N-wave, which would correspond to an N-wave duration of over $1 \mathrm{~s}$.

To the present author's knowledge, such long-duration $\mathrm{N}$-waves have not been observed before. A simple calculation of the Mach angle from the hyperbola contours in Fig.
14 yields a Mach number of approximately $M=14$. From a typical shuttle reentry profile, this Mach number corresponds to an altitude of approximately $55 \mathrm{~km}$. Computing the $\mathrm{N}$-wave duration from the standard approximate relations (Whitham, 1974) gives an N-wave duration of no more than $0.8 \mathrm{~s}$. However, the accuracy of the estimate for such high altitude and Mach number is difficult to assess. Long $\mathrm{N}$-wave durations up to $0.7 \mathrm{~s}$ have been observed from the space shuttle reentry using pressure transducers (Garcia et al., 1985), for a sonic boom estimated to have originated from the shuttle at $M=5.87$ at an altitude of $39.4 \mathrm{~km}$, which is still much later in reentry than the sonic booms recorded in Washington. The appearance of the two peaks on such widely separated sites does rule out local geological effects.

\section{MYSTERY BOOMS}

In the latter half of 1991 and early 1992, the U.S.G.S. office in Pasadena received a number of calls from the general public concerning "mystery booms" heard in southern California. Initially the events were assumed to be earthquakes, but further analysis of the seismograph records suggested sonic booms as the most likely source. An initial analysis of the seismic signals by the U.S.G.S. by attempting to fit hyperbola to the arrival time data for 25 sites near the coast attributed the sonic booms to a source flying at high altitude and high Mach number. These reports were picked up in the popular press and attributed to a top-secret hypersonic Aurora spyplane. A unique feature of the events was that all occurred on Thursday morning at approximately 0700, as shown in Table I.

Following the early claims, the Air Force commissioned MIT Lincoln Labs to investigate the incidents. The available seismograph records for 41 sites for the October 1991 event were analyzed. Again, the arrival times were fit as hyperbola, although an attempt was made to include the effects of vehicle deceleration and atmospheric refraction. The disturbances were attributed to the sonic booms from two F-4 Phantoms returning to Edwards AFB, flying supersonic near Mach 1 overland. None of the sites examined by Lincoln Labs included the third boom mentioned later.

In view of the above-mentioned disagreement, the October 1991 and January 1992 events were analyzed in the present study. The raw seismograph time data were obtained and analyzed for all 209 available sites for both events. Arrival times were chosen from the data and contoured without any assumptions concerning the shape of the time contours.

On the 31 October 1991 event, three booms are clearly distinguished on the time traces. The first boom appears on 90 sites throughout the seismic network. The boom dies out as one moves east and is not seen on the easternmost sites. The first boom is generally followed by a second boom which appears at the largest number of sites, 104, at an average of $83 \mathrm{~s}$ later. A third boom appears only at 30 of the easternmost sites, an average of $84 \mathrm{~s}$ after the second boom. The contours of arrival times are shown in Fig. 16 for each of the three booms identified. The triangle symbols represent seismic sites for which data were available, and filled triangles show the sites which detected each boom. 


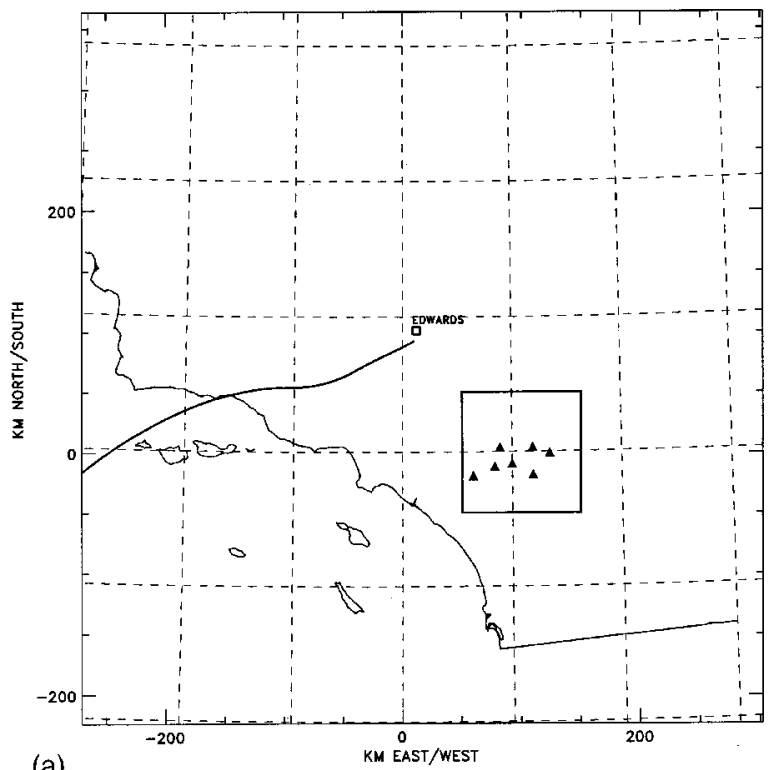

(a)
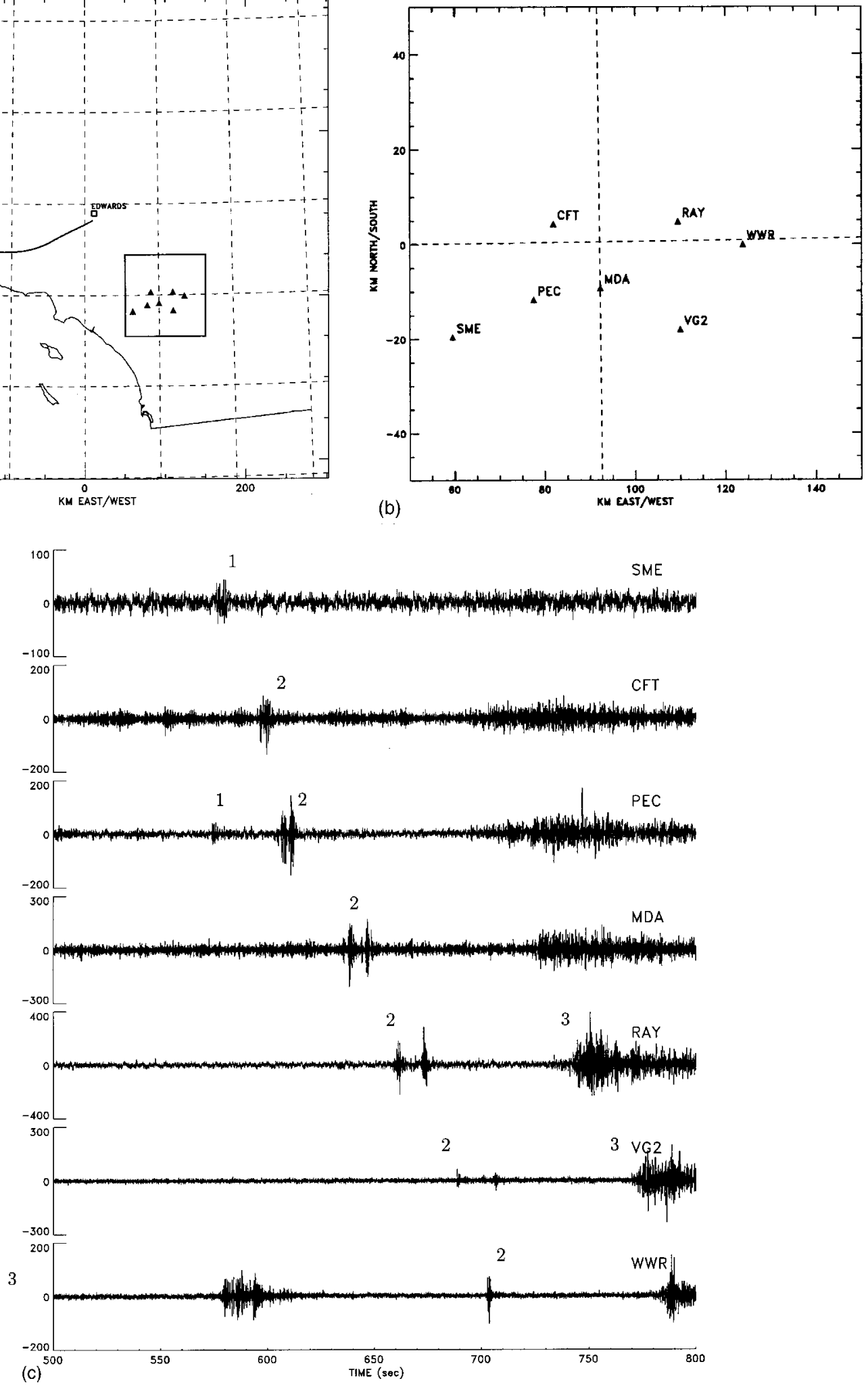

FIG. 12. (a) Seismic station locations relative to the STS-42 trajectory, (b) map inset, and (c) time traces from selected seismic stations within the secondary carpet predicted by ray-tracing for STS-42 reentry. Time traces record ground motion, vertical scale is voltage output in counts.

The northern limit of detection of the sonic boom is clearly defined, since a large number of sites in the northeast did not detect the boom. This is consistent with the low amplitude of the boom observed near the northern boundary. However, the southern edge of the boom carpet is not well defined due to the lack of seismograph sites further south in
Mexico. The booms show a relatively high amplitude at the southern sites which suggests the boom carpet may extend further south. Twelve additional sites in Mexico logged no unusual activity for that morning. However, since the actual seismographic data are not available, the sites are not included in this report. 


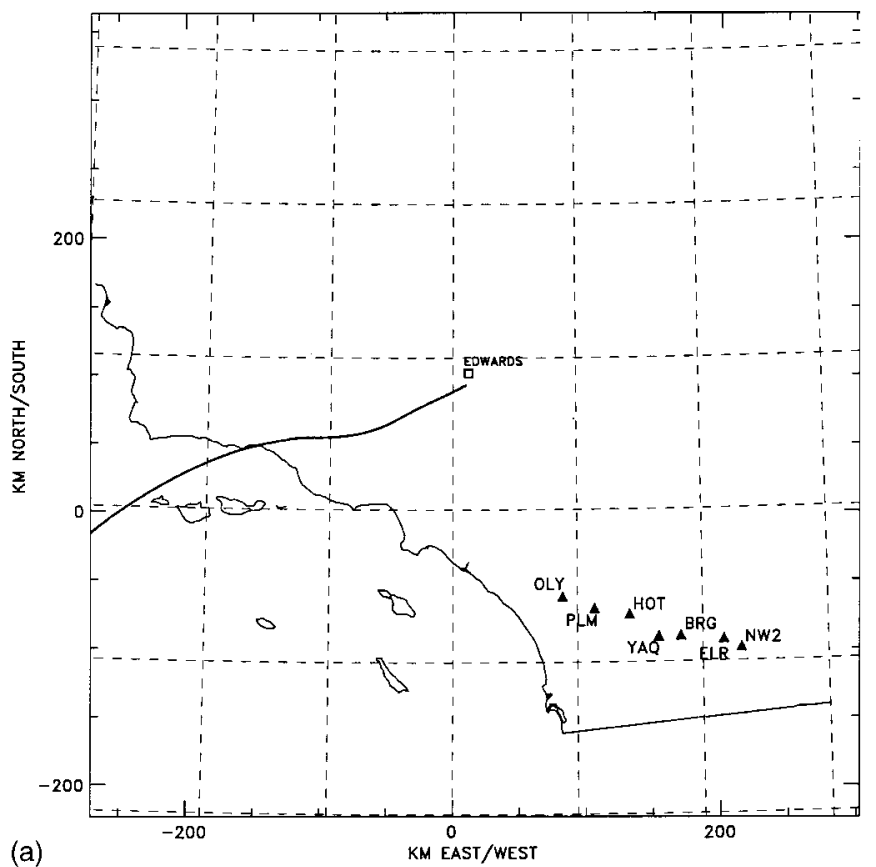

(a)

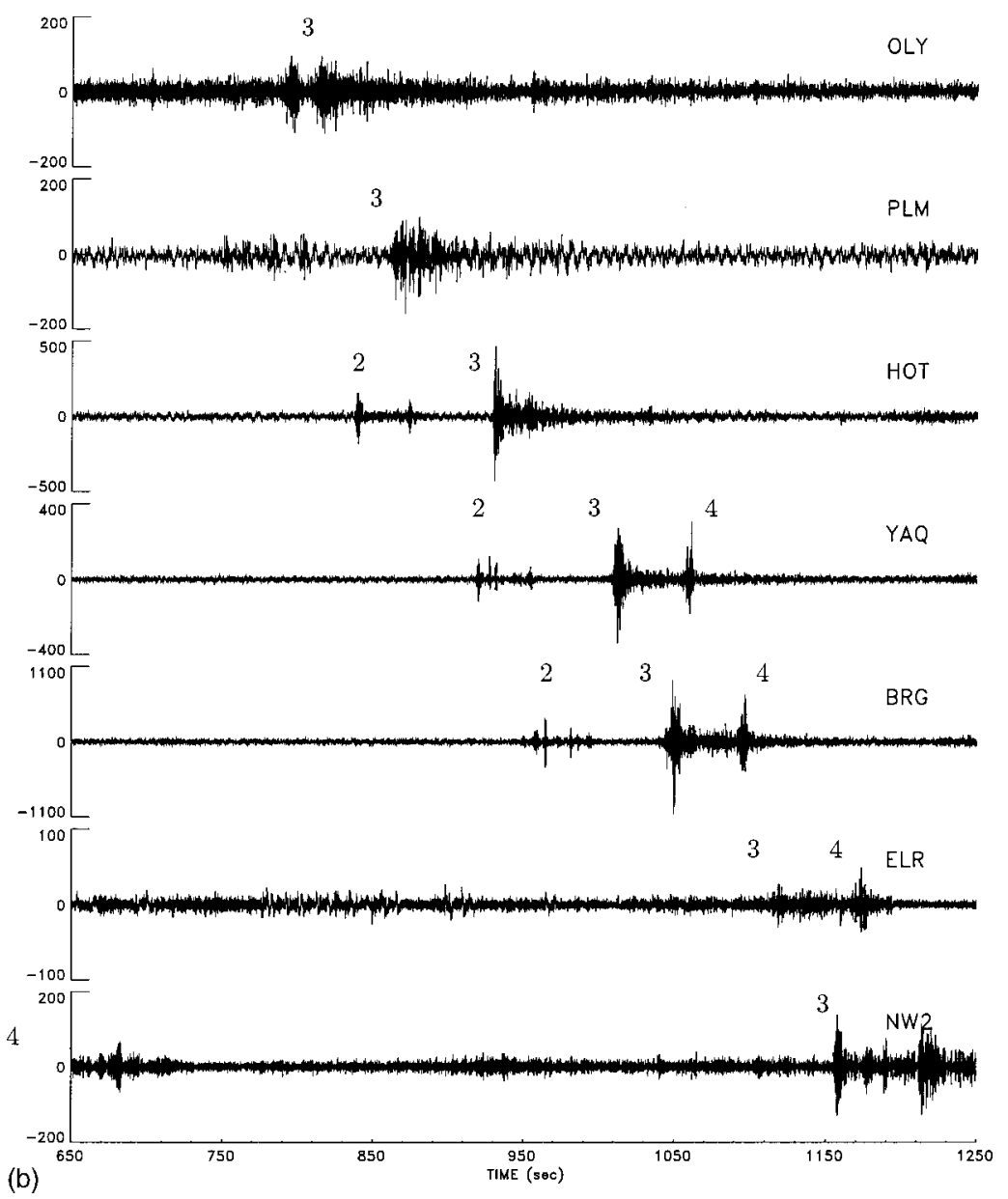

FIG. 13. (a) Seismic station locations relative to the STS-42 trajectory and (b) time traces from line of seismic stations outside the secondary carpet predicted by ray-tracing for STS-42 reentry. Time traces record ground motion, vertical scale is voltage output in counts.
A second event, from 30 January 1992, was also examined in detail and arrival time contours for the three booms observed are shown in Fig. 17. The same pattern of three disturbances is observed: the first boom on the western sites, the second across the entire network, and the third only on the eastern sites. The booms were detected across the entire network from west to east, but the booms were confined to a narrower north to south band.

Only one of the events examined does not display the circular patterns stretching from west to east characteristic of the above two events. The boom from Wednesday, 30 September 1992 is a narrow circular pattern extending from 


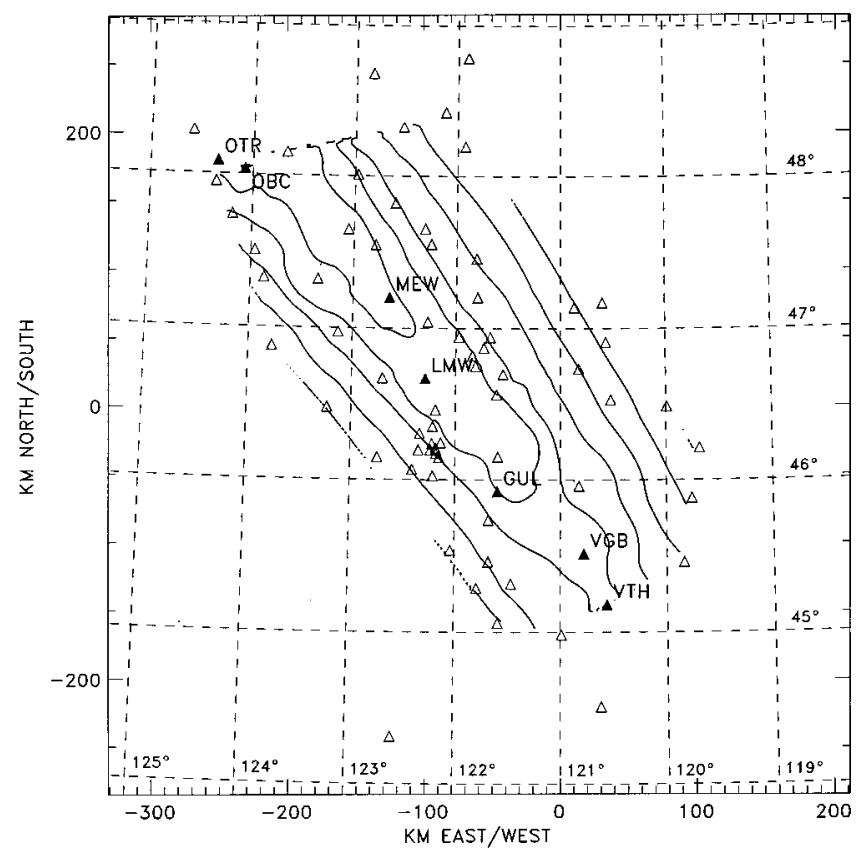

FIG. 14. Arrival time contours from seismic data for the December 1992 reentry of space shuttle Discovery over seismic network in Washington and Oregon. Time traces record ground motion, vertical scale is voltage output in counts. (Data supplied by Dr. A. Qamar, University of Washington.) south to north. The center of the circular pattern lies offshore, south of Catalina Island.

The analysis of the complete set of data eliminates both of the early theories for the source of the mystery booms. The lack of characteristic $\mathrm{N}$-wave signatures and the fact that no booms were detected on the northwestern sites rules out the original theory of a high-speed aircraft flying north off the coast. At the speeds predicted (Mach 5-6), one would expect to see strong $\mathrm{N}$-wave signatures with high amplitude near the coast, as with the shuttle reentry booms. The Lincoln Lab theory of two aircraft flying essentially down the center of the boom pattern fails to explain the three events detected. The aircraft would have to be flying at a speed of approximately Mach 1 relative to ground sound speed which would place the aircraft at or near the cutoff velocity for their altitude. In the case of a single aircraft, the first boom would be considered the primary boom carpet, and the second and third booms would be secondary booms. However, this single aircraft theory can be ruled out, since indirect booms would not be expected to appear under the aircraft track.

From the complete analysis, all the observed booms appear to be indirect booms from a source offshore propagated

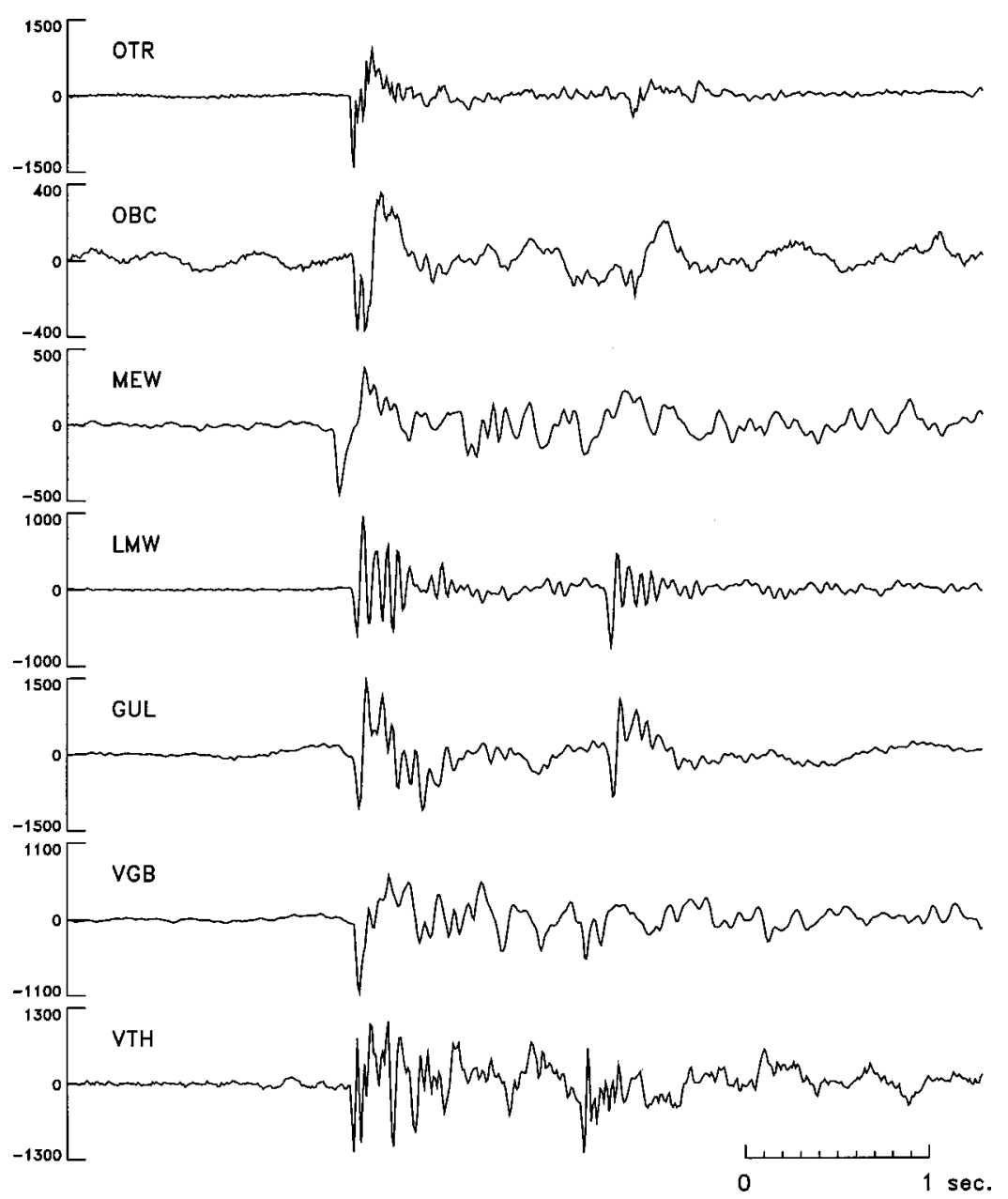

FIG. 15. Seismic traces for stations shown in Fig. 14 for December 1992 reentry of space shuttle Discovery. (Seismic data supplied by Dr. A. Qamar, University of Washington.) 

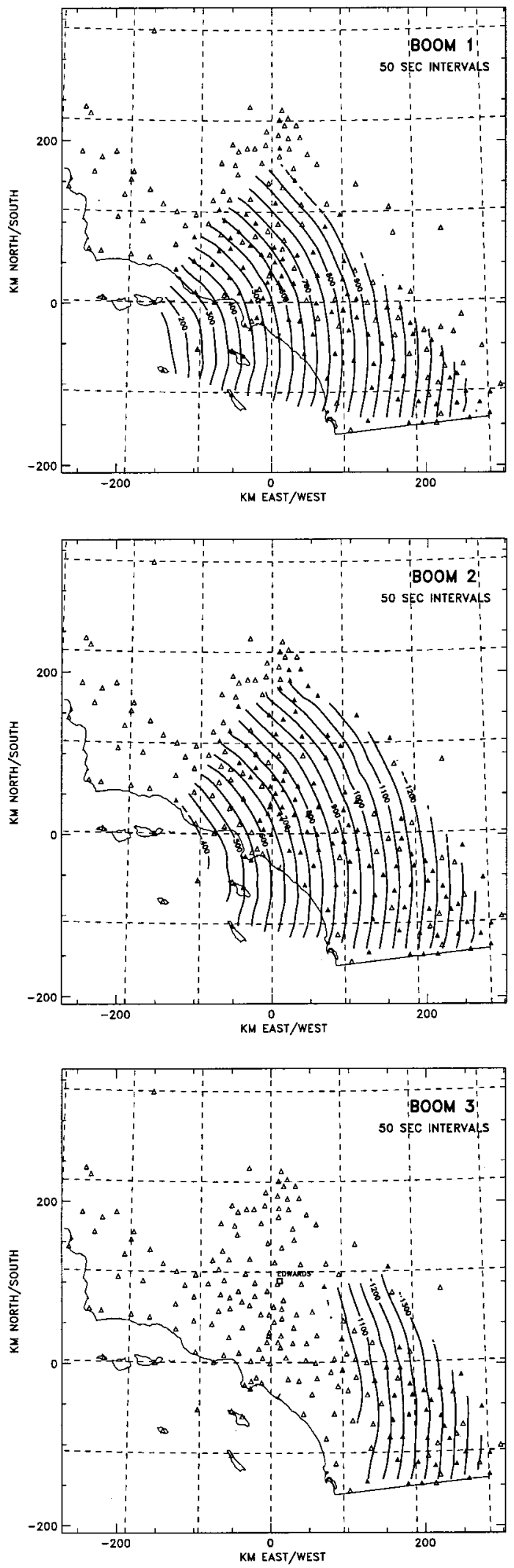

FIG. 16. Arrival time contours generated from seismic data for 31 October 1991 "mystery boom."

inland by high winds. Southern California typically has strong jet stream winds and stratospheric winds blowingfrom west to east. Such anomalous sound propagation is well known, and mystery booms attributed to aircraft are not a new phenomenon. In the late 1970s, a series of East Coast
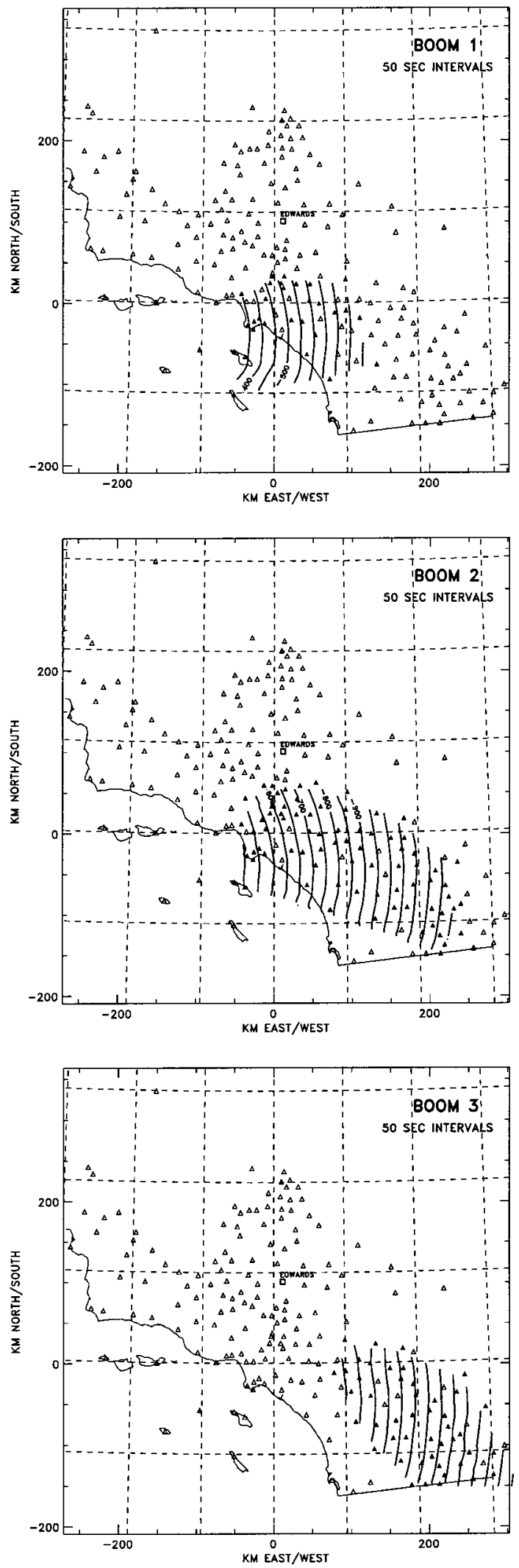

FIG. 17. Arrival time contours generated from seismic data for 30 January 1992 "mystery boom."

mystery booms occurred. Although a wide range of phenomena were grouped into the "mystery booms," the majority were attributed to indirect sonic booms from the Concorde (Rickley and Pierce, 1980) and sonic booms from military aircraft maneuvering offshore. Similar propagation of sonic 


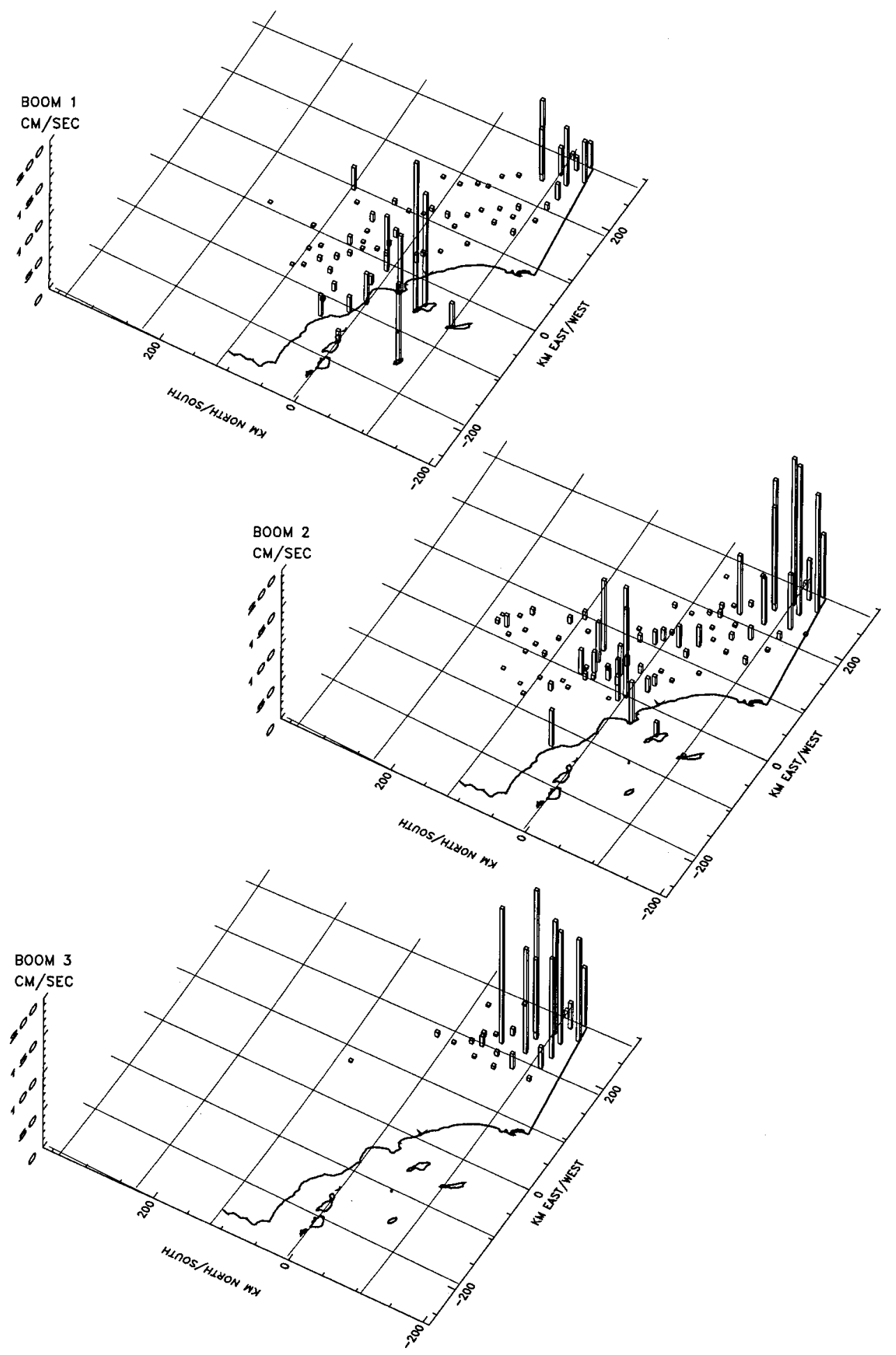

FIG. 18. Ground velocity magnitude $(\mathrm{cm} / \mathrm{s})$ for 31 October 1991 events, corrected for instrument response. All amplitudes over 200 are plotted as magnitude 200 for clarity.

booms over $100 \mathrm{~km}$ by the high jet stream winds have been observed in Tucson (Wood, 1975).

The magnitudes of the ground velocity for the 31 October 1991 events are shown in Fig. 18. Magnitudes are corrected for instrument response; however, no attempt is made to incorporate local site surface properties. For clarity, all amplitudes over 200 are plotted as 200. Higher ground velocities are found offshore, near the theorized source of the sonic booms. The large amplitudes on the easternmost sites seem to be due to local ground properties near the sites. Using the estimate of $1.5-2 \mu \mathrm{m} / \mathrm{s}$ per $\mathrm{Pa}$ of overpressure, the
TABLE I. Mystery boom occurrences. The October 1991 and January 1992 events are analyzed in the current work.

\begin{tabular}{cc}
\hline \hline Time & \multicolumn{1}{c}{ Date } \\
\hline 6:34 PDT & Thu 27 June 1991 \\
6:46 PST & Thu 31 Oct. 1991 \\
6:43 PST & Thu 21 Nov. 1991 \\
7:17 PST & Thu 30 Jan. 1992 \\
6:59 PST & Thu 16 Apr. 1992 \\
Unknown & Thu 18 June 1992 \\
6:38 PDT & Thu 15 Oct. 1992 \\
\hline \hline
\end{tabular}


ground velocity amplitudes correspond to the range of average pressures $0.15-0.2 \mathrm{~Pa}$ observed for Concorde indirect sonic booms (Rickley and Pierce, 1980).

An attempt to associate the mystery booms with specific flight operations from any of the local military bases has been unsuccessful. Local military bases reported no unusual activity on the dates of the mystery booms; in particular, the Pacific Missile Test Range, which operates offshore from Point Mugu, reported no supersonic flight operations on the mornings of the October 1991 or January 1992 events.

\section{CONCLUSION}

The seismic network in southern California has provided the first opportunity to study the size and shape of indirect sonic boom carpets over a large area. The high density of the sites and large ground coverage allow analysis of the direct and indirect boom patterns on both sides of the flight trajectory, and the development of the booms can be followed over several hundred kilometers. The recent addition of pressure transducers at selected TERRAscope sites remedies the only significant weakness of the seismic data, the difficulty of predicting amplitudes.

From analysis of the space shuttle STS-42 reentry, the ground patterns are extremely complex. Ray theory fails to predict indirect sonic boom arrival times, observed multiple booms within the first shadow region, and extensive overlap of the multiple refracted sonic booms. The extensive ground coverage of the "mystery boom" and shuttle reentry booms suggest exposure under the real atmosphere is much larger than previously expected.

The inverse problem of predicting the aircraft trajectory from the ground arrival times is more difficult. Nonetheless, using the seismic network data, we were able to identify the source of the "mystery booms" as indirect booms propagated from offshore operations. However, careful study of the seismic data is required to identify direct and indirect sonic boom carpets before attempting to make predictions about the trajectory.

\section{ACKNOWLEDGMENTS}

Seismic data and instrument information for the Southern California seismic network were kindly provided by Dr.
H. Kanamori, Caltech Seismological Laboratory, and Dr. J. Mori, U.S.G.S., Pasadena. Seismic data for the Discovery reentry were supplied by Dr. A. Qamar, University of Washington. Shuttle trajectory information was courtesy of Gene Stansbury and Joel Montalbano of NASA. Additional thanks are due to Dr. R. Meyer, Dr. J. Ehernberger, Dr. D. Lux, and Bob Cohn of NASA Dryden, and Dr. J. Greene of JPL for allowing us to participate in the SR-71 flight.

Balachandran, N., Donn, W., and Rind, D. (1977). "Concorde Sonic Booms as an Atmospheric Probe," Science 197, 47-49.

Ben Menachem, A., and Singh, S. (1981). Seismic Waves and Sources (Springer-Verlag, New York).

Cook, J., and Goforth, T. (1970). "Ground Motion from Sonic Booms," J. Aircr. 7, 126-129.

de Violini, R. (1967). "Climactic Handbook for Point Mugu and San Nicolas Island, Volume I, Surface Data," PMR-MR-67-2.

de Violini, R. (1969). "Climactic Handbook for Point Mugu and San Nicolas Island, Volume I, Upper-Air Data," PMR-MR-69-7.

Garcia, F., Jones, J., and Henderson, H. (1985). "Correlation of Predicted and Measured Sonic Boom Characteristics From the Reentry of STS-1 Orbiter," NASA TP-2475.

Goforth, T., and McDonald, J. (1968). "Seismic Effects of Sonic Booms," NASA CR-1137.

Kanamori, H., Mori, J., Sturtevant, B., Anderson, D., and Heaton, T. (1992). "Seismic excitation by space shuttles," Shock Waves 2, 89-96.

Meteorology Group, Range Commanders Council (1983). "Range Reference Atmosphere 0-70 Km Altitude: Edwards AFB, California," Doc. 366-83.

Onyeowu, R. (1975). "Diffraction of sonic boom past the nominal edge of the corridor," J. Acoust. Soc. Am. 58, 326-330.

Pierce, A. (1981). Acoustics: An Introduction to Its Physical Principles and Applications (McGraw-Hill, New York).

Qamar, A. (1993). "Seismic excitation by atmospheric disturbances: the Dec. 1992 Space Shuttle and a fireball in Jan. 1989," SSA abstr, April 1993.

Rickley, E., and Pierce, A. (1980). "Detection and Assessment of Secondary Sonic Booms in New England," FAA-AEE-80-22.

United States Committee on Extension to the Standard Atmosphere (1966). U.S. Standard Atmosphere Supplements (U.S. Govt. Printing Office, Washington, DC).

Whitham, G. (1974). Linear and Nonlinear Waves (Wiley, New York).

Wood, R. (1975). "Jet Stream-Sonic Boom Phenomena, Tucson, Arizona, April 1975," Weatherwise 28, 152-155. 